\author{
Military Technical College \\ Kobry El-Kobbah, \\ Cairo, Egypt.
}

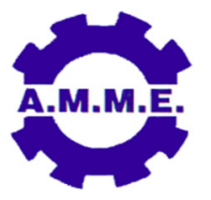
$16^{\text {th }}$ International Conference on Applied Mechanics and Mechanical Engineering.

\title{
INVESTIGATION OF THE DISPERSION OF UNGUIDED FINNED MISSILE
}

\author{
O. K. Mahmoud ${ }^{1}$, H. AbdELbaset ${ }^{2}$ and M. A. Alsanabawy ${ }^{3}$
}

\begin{abstract}
The problem of accuracy of fire and its impact on weapon effectiveness presents a major concern of munitions designer. Many factors can be considered to improve the missile dispersion. Some are related to the missile itself, others are related to the launcher or the mutual effects between the missile and the launcher. The environmental launching conditions have a prime impact on the firing accuracy. The present work introduces simulation and experimental studies dealing with individual parameters and their influential weights concerning their impact on dispersion of a finned missile. The effects of the initial firing parameters, namely initial mass, initial launching angle, initial velocity and location of center of gravity are investigated. For each case the parameter was varied within certain limits to simulate the production inaccuracy, or approximations during design and the initial errors that can be impeded in the launcher and aiming devices. The trajectory was calculated using PRODAS software and compared with the real flight data. Comparisons of predicted and experimental results have proven satisfactory matching.
\end{abstract}

\section{KEY WORDS}

Firing tables, flight trajectory, anti-submarine bomb and PRODAS.

\footnotetext{
${ }^{1}$ Egyptian Armed Forces, Egypt. Email: osamamoka@gmail.com.

${ }^{2}$ Center of Excellency and Technology, Ministry of Military Production, Email: hanan.mohmed76@yahoo.com.

${ }^{3}$ Egyptian Armed Forces, Egypt. Email: allamm@link.net.
} 


\section{INTRODUCTION}

Dispersion of unguided missiles can be a result of many factors. These factors can be classified according to different production and flight phases.

Causes attributed to production include thrust and fin misalignments, longitudinal axis, nozzle alignment, fin mounting errors, tolerances in the design, manufacturing, measurement, and structural bending [1]. Variation of the weights of rocket motor, propellant, and structure are critical parameters that affect the flight trajectory. Launcher dynamics [4], ignition shock, acoustics, vibration, launcher deflection, inadequate structural rigidity, launcher tip-off effect, finite length launcher, center of gravity shift and pitching down are further set of important parameters. Also, launcher setting errors can be shown as, Inclined launchers, elevation and azimuth, sensitivity at higher elevations. Causes due to atmospheric conditions are manifested by wind effects, head, tail, and cross winds, measurement inaccuracy, wind variability between the time of measurement and the time of launch [3].

Measurement inaccuracy of rocket center of gravity and its shift during flight are of dominant effect. Variation in rocket motor performance, temperature effect on propellant, composition, specific impulse, and burn rate can greatly affect the dispersion. Uncertainty in estimating aerodynamic coefficients (theoretical or experimental through wind tunnel measurements) can generally mislead the trajectory prediction [2].

\section{PLAN OF WORK}

For investigating the effect of variation of the initial mass, initial launching velocity, launching angle and longitudinal center of gravity, the following plan of work has been accomplished. The main design of an anti-submarine bomb ASMB was realized using CAD software to calculate each individual part. Then, the mass and all other mechanical and physical properties were concluded and analyzed. The result of this stage was the initial mass $m_{0}$ and all inertia properties of the ASMB. In the production phase, all the used tolerances were carried out according to previous experience in production of rockets and shells. Hence, the tolerances were made in accordance with the military standards and available production facilities. All the produced parts were inspected and sorted in a way to keep the final missile with its allowable tolerances.

Before firing tests, 6DOF simulation was carried out using PRODAS software for the selected ASMB. Different flight inputs were investigated. Each run was completed for the input data: initial nominal mass of the missile $m_{0}$, position of longitudinal center of gravity $X_{c g}$, launch velocity $V_{o}$ and launch angle. These parameters were varied within close limits to simulate the potential production and launch errors. Then, a set of trajectories was obtained as function of the variable inputs and the relative variations in range were recorded for further investigation.

Real field firing tests were performed for 6 ASMB's. Flight trajectory data were recorded using RADAR. These data were then compared with the corresponding prediction obtained by PRODAS software. 


\section{CASE STUDY}

Basic data of the original and modified anti-submarine bomb are presented in Table 1. The main construction of the ASMB is introduced in Fig. 1.

Investigation of factors contributing to the trajectory dispersion characterizes the main object of the present work. The following shooting parameters were varied to find the most effective factors in the dispersion analysis. These parameters were: bomb total weight, shooting angle, launching velocity, and launching angle respectively.

Table 1. Main data of the basic and modified ASMB.

\begin{tabular}{|l|c|c|}
\hline \multicolumn{1}{|c|}{ Data } & Original Bomb & $\begin{array}{c}\text { Modified } \\
\text { Bomb }\end{array}$ \\
\hline Number of Solid propellant grains & 5 & 7 \\
\hline Mass, [kg] & 71.5 & 90 \\
\hline Thrust, [N] & 1230 & 36720 \\
\hline ASMB total length, [mm] & 1218 & 1229.5 \\
\hline Rocket motor outer diameter, [mm] & 160 & 170 \\
\hline Number of rocket motor nozzles & 6 & 7 \\
\hline Warhead diameter, [mm] & 253 & 253 \\
\hline Launching velocity, $\mathrm{V}_{\mathrm{o}}[\mathrm{m} / \mathrm{s}]$ & 23 & 23 \\
\hline Maximum velocity, $[\mathrm{m} / \mathrm{s}]$ & 120 & 240 \\
\hline Burning time, $[\mathrm{s}]$ & $25-35$ & $40-65$ \\
\hline Launching angles, $\left[{ }^{\circ}\right]$ & $12-45$ & $12-45$ \\
\hline
\end{tabular}

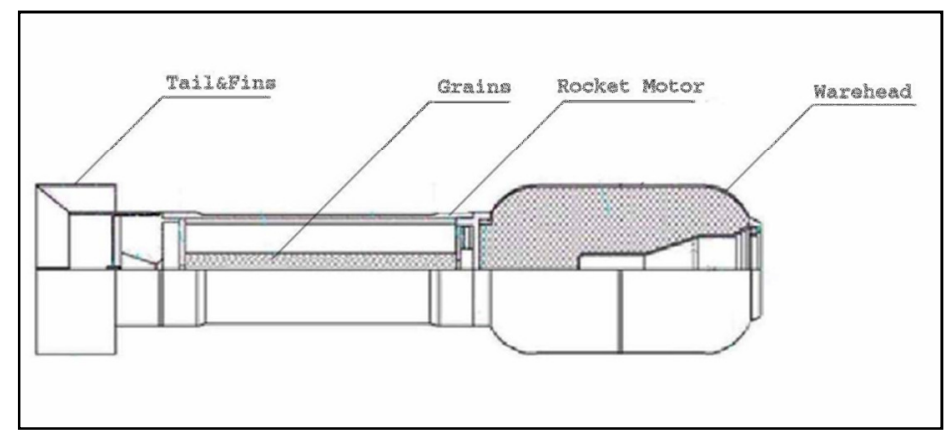

Fig. 1. Main construction of ASMB.

\section{RESULTS}

\section{Real Firing Flight Data}

Six ASMB's were fired through flight test. RADAR was used to trace each bomb trajectory and all of its flight parameters were measured. The rounds were fired at different elevation angles. Namely, two rounds were shot at angle of elevation $15^{\circ}$, 
two rounds at $41^{\circ}$, one round at $41.5^{\circ}$, and one round at $45^{\circ}$. Some of the measured data are listed in Table 2. The flight trajectories for the six rounds are also recorded.

Table 2. Maximum values for some parameters.

\begin{tabular}{|l|c|c|c|c|c|c|}
\hline $\begin{array}{c}\text { Elevation Angle, } \\
\boldsymbol{\theta}_{\mathbf{o}}\left[{ }^{\circ}\right]\end{array}$ & $\mathbf{1 5}^{\circ}$ & $\mathbf{1 5}^{\circ}$ & $\mathbf{4 1 . 5}^{\circ}$ & $\mathbf{4 1}^{\circ}$ & $\mathbf{4 1 . 5}^{\circ}$ & $\mathbf{4 5}^{\circ}$ \\
\hline Flight Time [s] & 9.9 & 9.1 & 26.6 & 27 & 30.3 & 28 \\
\hline Maximum Range [m] & $1,872.2$ & $1,765.69$ & $3,758.4$ & $3,565.68$ & $3,710.5$ & $3,552.97$ \\
\hline Summit point [m] & 78.744 & 106.85 & $1,090.73$ & $1,108.2$ & $1,134.13$ & 995.14 \\
\hline $\begin{array}{l}\text { Burnout Velocity } \\
{[\mathrm{m} / \mathrm{s}]}\end{array}$ & 210.42 & 210.23 & 215.0 & 225.70 & 202.11 & 197.50 \\
\hline
\end{tabular}

For the two bombs fired at 15 degree, the measured ranges were 1872.2 and 1765.69 [m], respectively. Each bomb flight range is about half that corresponding to firing angle $45^{\circ}$.

It is noticed that the bomb fired at elevation angle 41.5 gave the maximum range, maximum height and maximum velocity.

It worth noting that, the two rounds shot at 15 deg have $8.7 \%$ difference in flight time, $6 \%$ difference in range, and $26.3 \%$ increase in height. Maximum velocities were almost the same. All the produced metal parts were under constrained and fixed tolerances during production.

The two rounds that were fired at $41^{\circ}$ have $1.5 \%$ difference in flight time, $5.4 \%$ difference in range, and $1.6 \%$ increase in height. Maximum velocities have a $4.74 \%$ difference. Figures 2, 3 and 4 present the real firing for the 6 bombs.

The values of maximum range and drift are listed in Table 3 . Normal distribution is used to calculate average, variance and standard deviation for the firing results.

\section{Computational Results for the ASMB}

The rocket motor of the ASMB was completely redesigned. The new version includes new parameters, namely, diameter, length, number of propellant grains, grain dimensions and nozzle block with different nozzles.

The thrust was recorded during a static firing test. Then a set of flight tests was carried out in the shooting range field. Each flight trajectory was recorded using a tracking RADAR and compared to that predicted using PRODAS.

A comparison between the predicted and measured flight data is introduced in Table 4. 


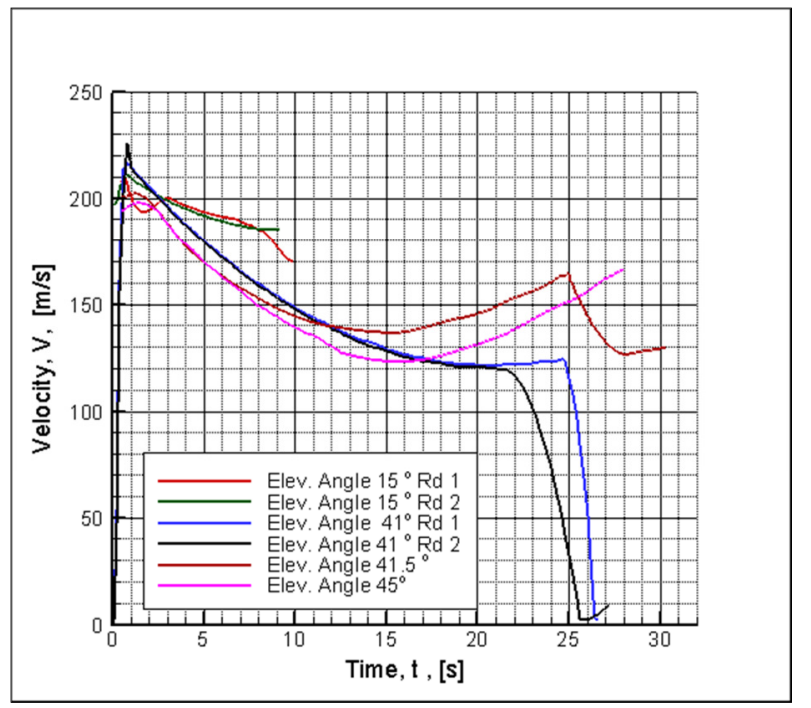

Fig. 2. Velocity versus time at different elevations.

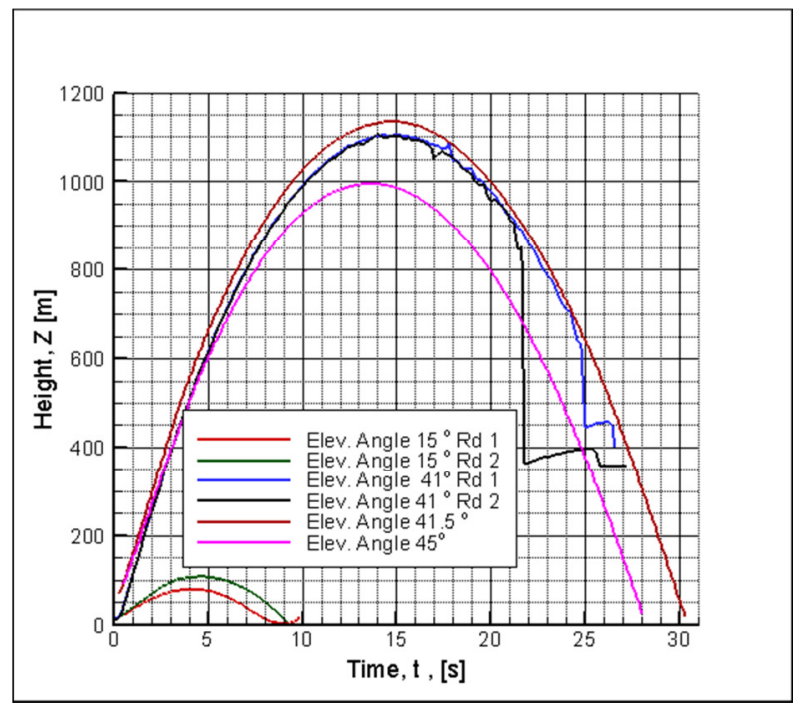

Fig. 3. Altitude versus time at different elevations.

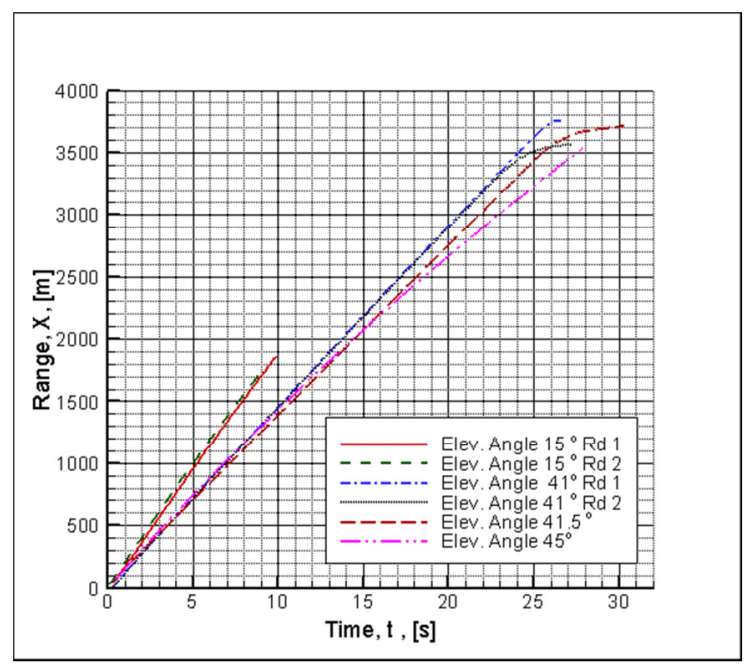

Fig. 4. Range versus time at different elevations

Table 3. Ranges $(X)$ and Summit Height $(Y)$.

\begin{tabular}{|c|c|c|}
\hline Elevation Angle $\boldsymbol{\theta}_{\boldsymbol{o}}\left[{ }^{\circ}\right]$ & $\mathbf{X}[\mathrm{m}]$ & $\mathbf{Y}[\mathbf{m}]$ \\
\hline 41.5 & $3,710.5$ & -232.8 \\
\hline 41.5 & $3,758.4$ & -228.9 \\
\hline 45 & $3,552.97$ & -208.8 \\
\hline 41 & $3,565.68$ & -232.56 \\
\hline 15 & $1,872.2$ & -59.515 \\
\hline 15 & $1,765.69$ & -98.23 \\
\hline Average & $3,037.57$ & -176.801 \\
\hline Variance & 987334.4 & 5982.52 \\
\hline Standard deviation & 947.92 & 77.35 \\
\hline
\end{tabular}


Table 4. Comparison between predicted and measured flight data.

\begin{tabular}{|c|c|c|c|c|c|c|}
\hline \multirow{2}{*}{$\begin{array}{c}\text { Shooting } \\
\text { (elevation) } \\
\text { angle [ }\end{array}$} & \multicolumn{2}{|c|}{ Range [m] } & \multicolumn{2}{c|}{ Time of flight [s] } & \multicolumn{2}{c|}{ Summit point [m] } \\
\cline { 2 - 7 } & Flight & Calculation & Flight & Calculation & Flight & Calculation \\
\hline 15 & 1872.2 & 2115.42 & 9.9 & 10.98 & 78.744 & 142.1 \\
\hline 15 & 1765.69 & 2115.42 & 9.1 & 10.98 & 106.85 & 142.1 \\
\hline 41 & 3758.4 & 3576.68 & 26.6 & 24.1 & 1090.73 & 386.32 \\
\hline 41 & 3565.68 & 3576.68 & 27 & 24.1 & 1108.2 & 704.7 \\
\hline 41.5 & 3710 & 3701.28 & 30.3 & 27.76 & 1134.1 & 933.23 \\
\hline 45 & 3552.9 & 3700.96 & 28 & 29.56 & 995.14 & 1058.96 \\
\hline
\end{tabular}

It is noted that the predicted results are generally very close to the real firing data. In particular, the accuracy in range is very high at firing angles around $41.5^{\circ}$, the optimum angle that corresponds to the maximum range.

\section{PARAMETRIC STUDY}

To complete the necessary data for constructing realistic firing tables for the modified $A S M B$, the effects of varying firing data on range and other flight parameters will be investigated. These parameters are center of gravity, mass, launch angle and launching velocity. Their impact on range, flight time, and summit height and burnout velocity will be examined at standard firing conditions.

\section{Center of gravity}

The center of gravity was shifted such that its distance from nose $X_{c g}$ varied from $1.45 \mathrm{D}$ to $1.8 \mathrm{D}$, in the positive direction, where $\mathrm{D}$ is the caliber of the bomb.

The bomb stability is secured for $\mathrm{X}_{\mathrm{cg}} \leq 1.8 \mathrm{D}$

Figures 5, 6,7 and 8 present the variation in trajectory parameters with the variation of axial center of gravity location. As the center of gravity is displaced from 1.45 to 1.8 calibers, range is increased by $3.1 \%$, time of flight is decreased by $3.3 \%$, burnout velocity is decreased by $2.5 \%$, and summit height is increased by $6.9 \%$.

\section{Mass Variation}

The nominal mass of $A S M B$ is $90 \mathrm{~kg}$ changed by $\pm 0.5 \mathrm{~kg}$, considering launching velocity $30 \mathrm{~m} / \mathrm{s}$, elevation angle $41.5^{\circ}$, and the original center of gravity location $\mathrm{X}_{\mathrm{cgo}}=408.69 \mathrm{~mm}$. Table 6 presents the maximum values of time, range, height, and velocity.

Figures $9,10,11$, and 12 present the variation of trajectory parameters with variation of ASMB mass. As a result of increasing the projectile mass while keeping the other parameters invariant, flight time decreases by $1.5 \%$, range decrease by $2.22 \%$ summit point height decreases by $3 \%$, and the burnout velocity decreases by $2.29 \%$. 


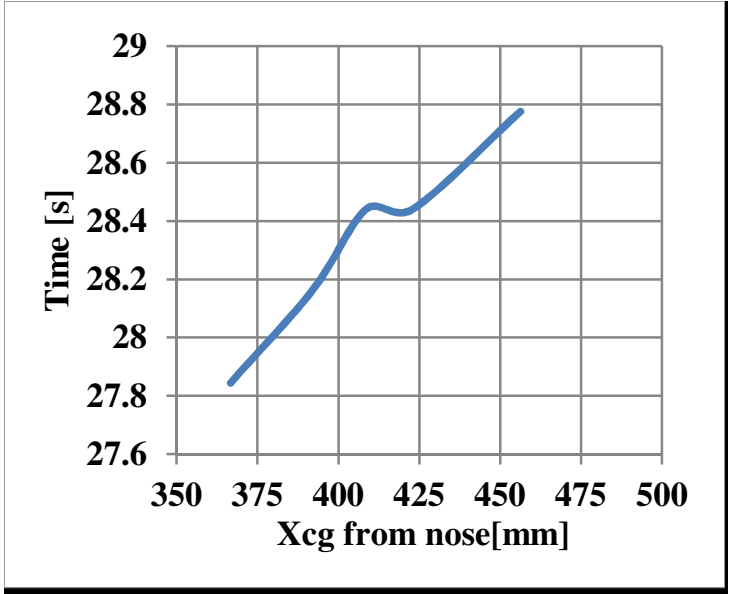

Fig. 5. Maximum time versus center of gravity shift with constant $\left(\mathrm{M}, \mathrm{V}_{0}, \theta_{0}\right)$.

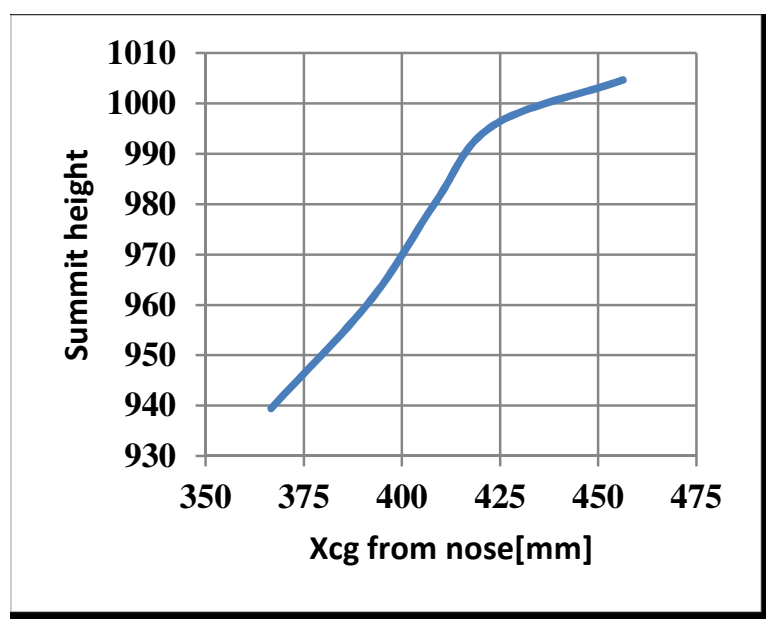

Fig. 7. Maximum height versus center of gravity shift with constant $\left(\mathrm{M}, \mathrm{V}_{0}, \theta_{0}\right)$.

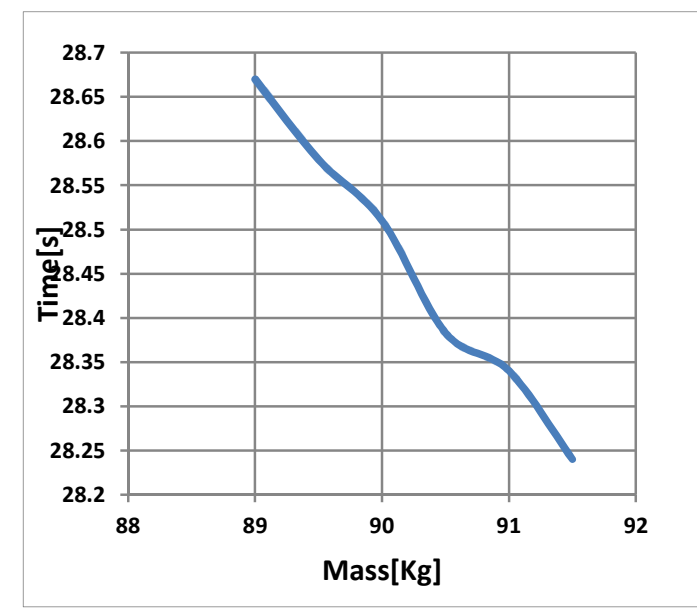

Fig. 9. Maximum time versus mass variation with constant $\left(\left(x_{c g}, \theta_{0}, v_{0}\right)\right.$.

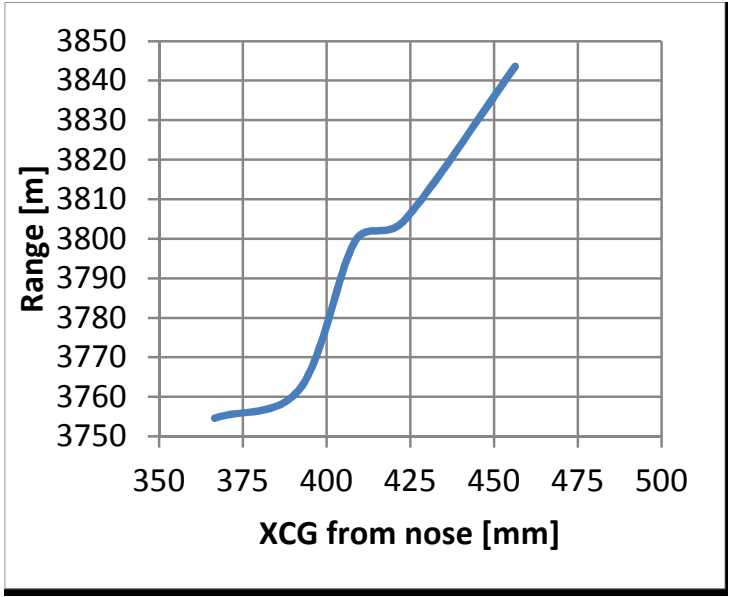

Fig. 6. Maximum range versus center of gravity shift with constant $\left(\mathrm{M}, \mathrm{V}_{0}, \theta_{0}\right)$.

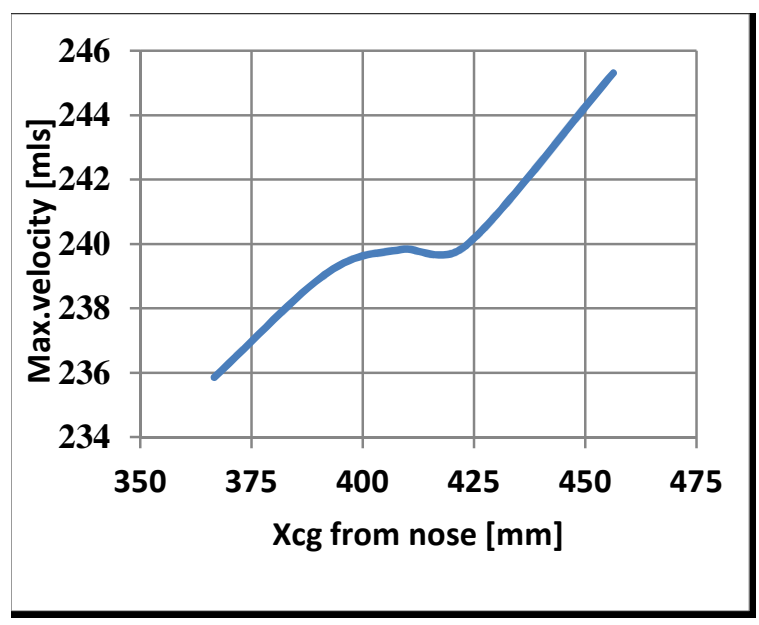

Fig. 8. Maximum velocity versus center of gravity shift with constant $\left(M, V_{0}, \theta_{0}\right)$.

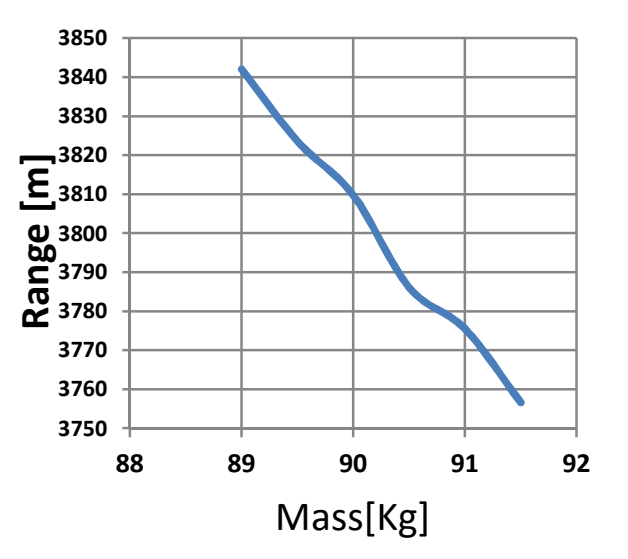

Fig. 10. Maximum range versus mass variation with constant $\left(\left(\mathrm{x}_{\mathrm{cg}}, \theta_{0}, \mathrm{v}_{0}\right)\right.$ 


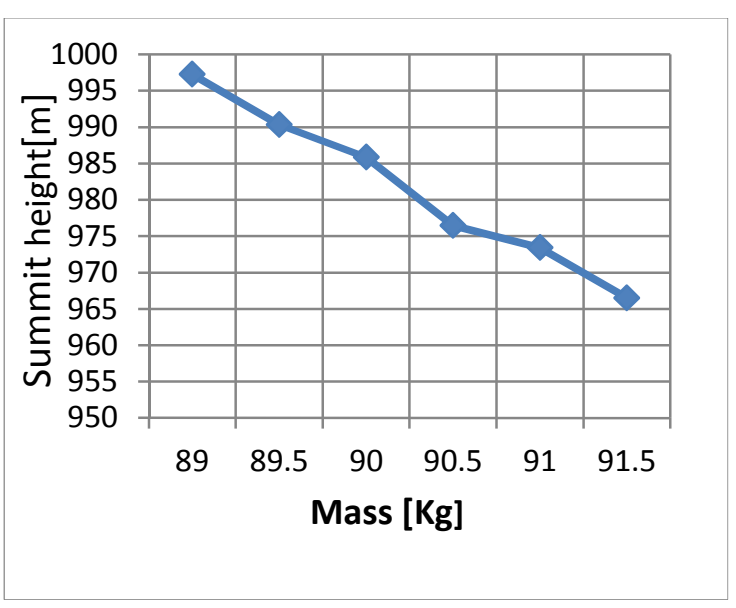

Fig. 11. Maximum height versus mass variation with constant $\left(\mathrm{x}_{\mathrm{cg}}, \theta_{0}, \mathrm{v}_{0}\right)$.

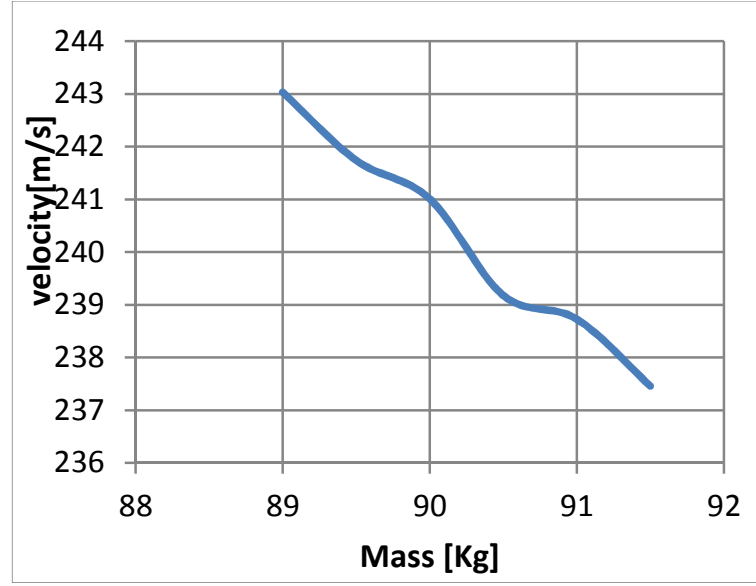

Fig. 12. Maximum velocity versus mass variation with constant $\left(\mathrm{x}_{\mathrm{cg}}, \theta_{0}, \mathrm{v}_{0}\right)$.

\section{Launching angle $\theta_{0}$}

The nominal elevation angle of $A S M B$ is 41.5 is varied within $\pm 0.5^{\circ}$. Other parameters are kept constant, namely velocity $=30 \mathrm{~m} / \mathrm{s}, X_{\mathrm{cg}}=408.69 \mathrm{~mm}$, and mass $=90 \mathrm{~kg}$. The maximum values of Time, range, summit height, and burnout velocity are presented in figures, 13, 14, 15, 16.

It can be shown that with variation of the launching angle, time of flight is increased by $4.85 \%$, range is increased by $0.4 \%$, summit height is increased by $10 \%$ and the maximum burnout velocity is deceased by $0.063 \%$.

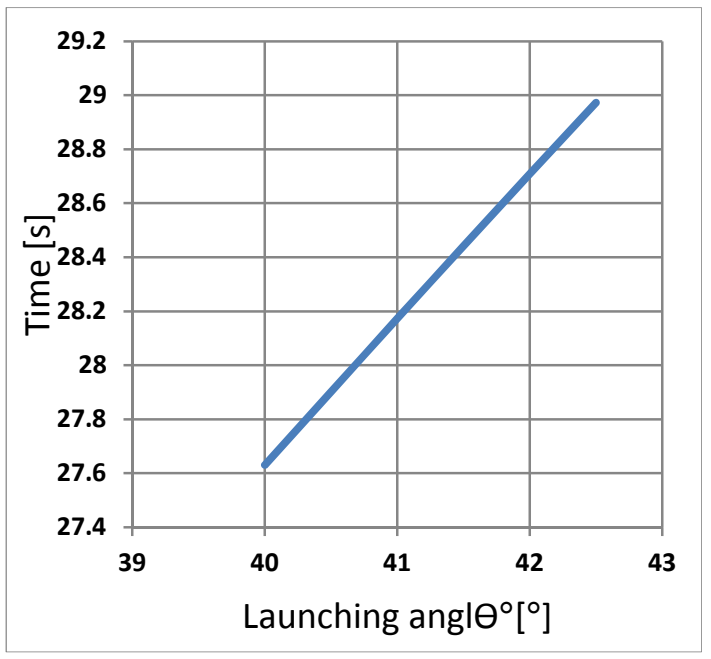

Fig. 13. Maximum time versus launching angle variation with constant $\left(\mathrm{x}_{\mathrm{cg}}, \mathrm{m}, \mathrm{v}_{0}\right)$

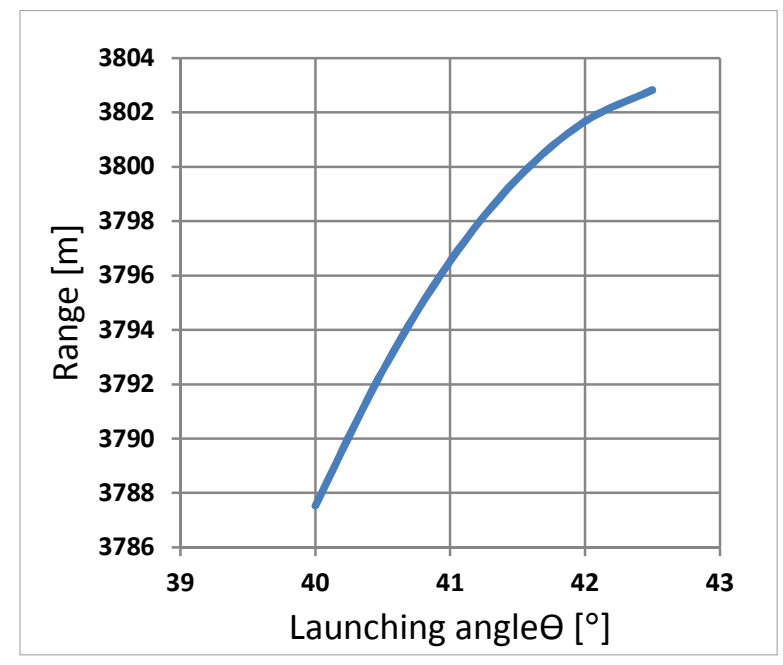

Fig. 14. Maximum range versus launching angle variation with constant

$$
\left(\mathrm{x}_{\mathrm{cg}}, \mathrm{m}, \mathrm{v}_{0}\right) \text {. }
$$




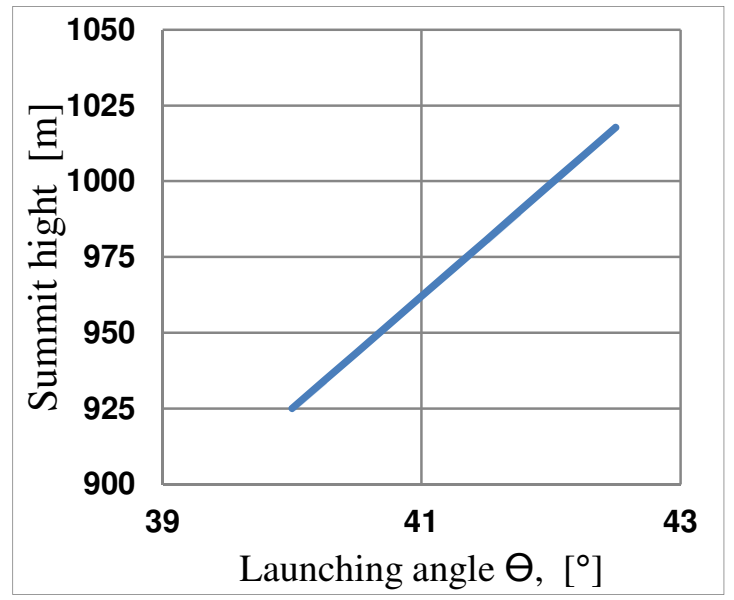

Fig. 15. Maximum height versus launching angle variation with constant $\left(x_{c g}, m, v_{0}\right)$.

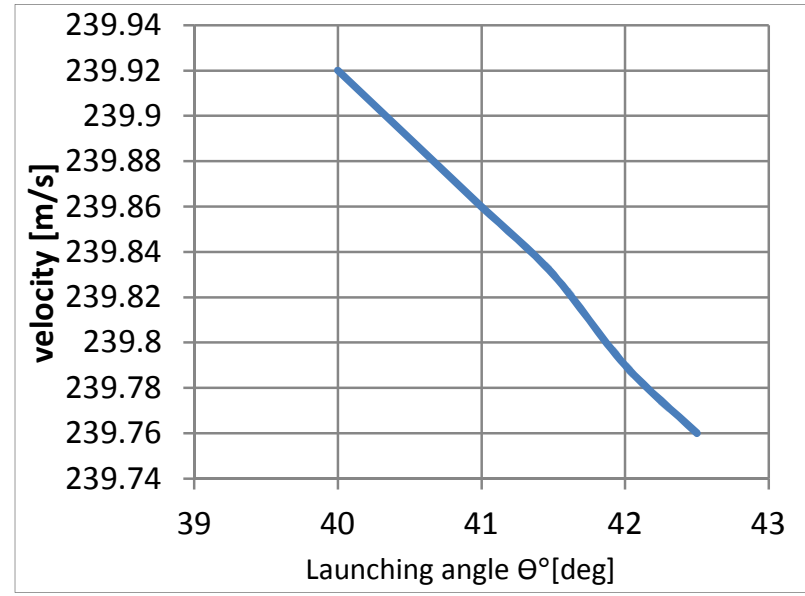

Fig. 16. Maximum velocity versus launching angle variation with constant $\left(\mathrm{x}_{\mathrm{cg}}, \mathrm{m}, \mathrm{v}_{0}\right)$.

\section{Launching Velocity}

The nominal launching Velocity $30 \mathrm{~m} / \mathrm{s}$ is varied within the range $\pm 1 \mathrm{~m} / \mathrm{s}$. Other parameters are kept constant, namely launching angle $\theta_{0}=41.5^{\circ}$, mass $=90 \mathrm{~kg}$, $X_{c g}=408.69 \mathrm{~mm}$. The maximum values of the four parameters are shown in Figures, 17, 18, 19, 20.

The variation of the muzzle velocity from $28 \mathrm{~m} / \mathrm{s}$ to $32 \mathrm{~m} / \mathrm{s}$ entails time of flight increase of $1.3 \%$, range increase of $1.72 \%$, summit height increase of $2.5 \%$ and maximum velocity increase of $1.6 \%$; where $\mathrm{m}$ is the initial mass of the $A S M B, V_{0}$ is the launching velocity and $\Theta_{0}$ is the launching angle.

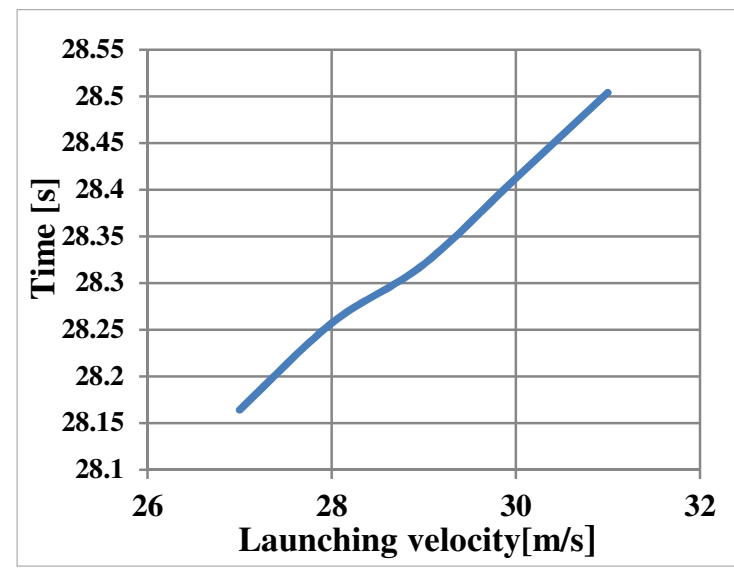

Fig.17. Maximum time versus launching velocity variation with constant $\left(x_{c g}, m\right.$, $\left.\theta_{0}\right)$.

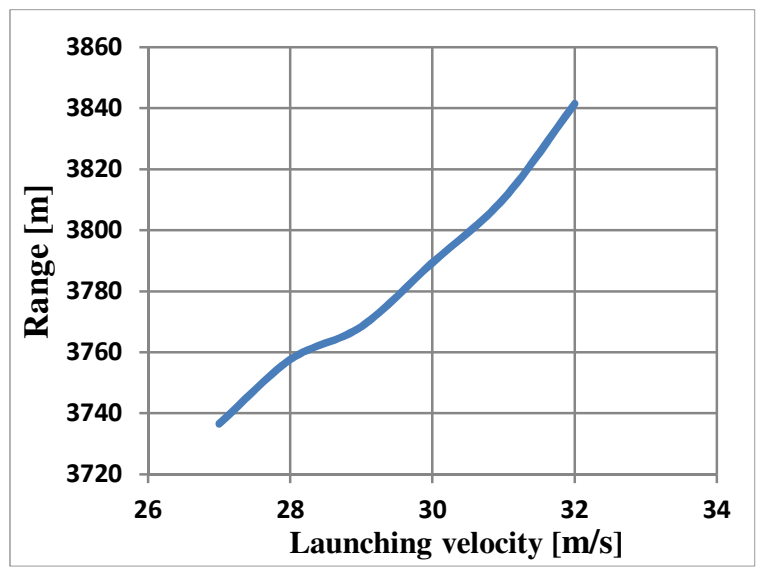

Fig. 18. Maximum range versus launching angle variation with constant $\left(x_{c g}, m, \theta_{0}\right)$. 


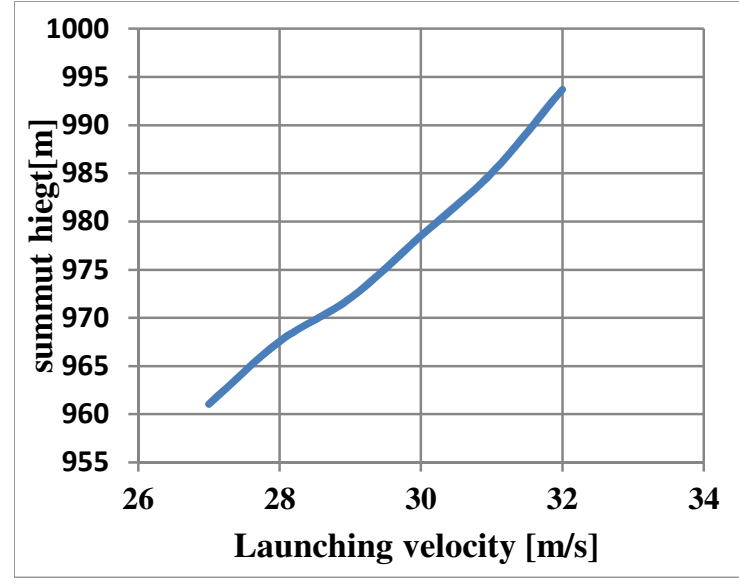

Fig.19. Maximum height versus launching angle variation with constant $\left(\mathrm{x}_{\mathrm{cg}}, \mathrm{m}, \theta_{0}\right)$.

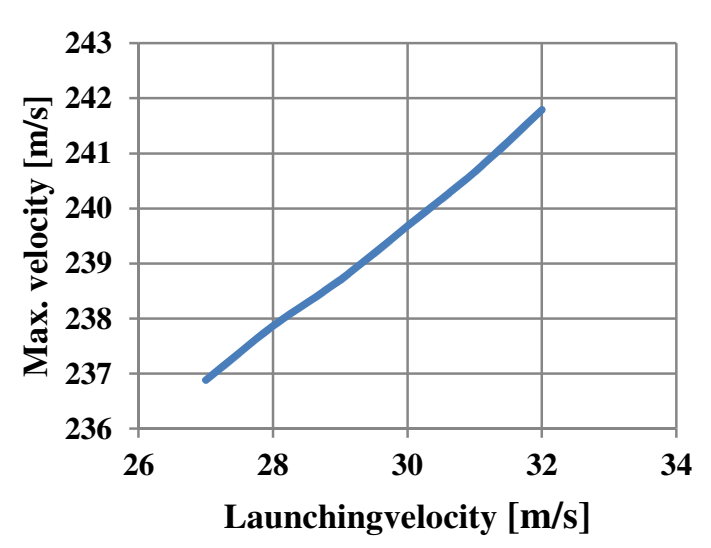

Fig. 20. Maximum velocity versus launching velocity variation with constant $\left(x_{\mathrm{cg}}, \mathrm{m}, \theta_{0}\right)$.

\section{CONCLUSION}

In the present work, four parameters were investigated which affects the impact point, namely mass, launching velocity, elevation angle and center of gravity. In an approach to simulate the production tolerances, design approximation and other random parameters, an individual small change in each parameter was produced and investigated separately. Its effect on the impact point was introduced. It was noticed that, the change in range varied from $0.4[\mathrm{~m}]$ to 3.1 . The most effective parameter in the range is center of gravity, it seems that the change in range is small as a result of small incremental and each effect was studied with constant the other parameters. On the other hand in real firing all parameters affecting in the same time so the change is clear even with the same angle, launching angle, mass and $X_{c g}$

\section{REFERENCES}

[1] Chin, S.S., "Missile Configuration Design", United States of America, McGrawHill, 1961.

[2] Arrow Tech Associates Balloting Analysis Uses June 2010.

[3] Field manual NO.6-40 MARINE CORPS WARFIGHTING PUPLICTION NO.31.6.19, HEADQURTERS department of the army, U.S. MARINE CORPS, Washington, DC, 23th April 1996

[4] D. Raducanu, I. Nedelcu, D. Safta, P. Somoiag and C.-E. Moldoveanu "Particularity Concerning Evaluation of Unguided Rocket Trajectories Deviation under the Disturbance Factors Action" Proceedings of the World Congress on Engineering, Vol. II, London, July 1 - 3 (2009). 